\title{
SER ADOLESCENTE COM TRANSTORNO DE APRENDIZAGEM: UM OLHAR DA FENOMENOLOGIA DE MERLEAU-PONTY
}

\section{Being an Adolescent with a Learning Disorder: A Look at Merleau-Ponty's Phenomenology}

Ser Adolescente con Trastorno de Aprendizaje: Una Mirada de la Fenomenología de MerleauPonty

\section{Être Adolescent avec un Trouble des Apprentissages : Un Regard sur la Phénoménologie de Merleau-Ponty}

10.5020/23590777.rs.v21iEsp1.e9376

\section{Roxanne Pucci de Mesquita Ibiapina iD 9 \\ Psicóloga graduada pela Universidade de Fortaleza (UNIFOR).}

\section{João Marcos de Araújo Leite (iD)}

Mestre em saúde coletiva pela Universidade de fortaleza (UNIFOR). Psicólogo graduado pela UNIFOR. Psicoterapeuta com formação em cínica humanista fenomenológica.

\section{Anna Karynne Melo (iD) 9}

Pós-doutora pela Universidade Federal do Ceará. Doutora em Saúde Coletiva pela Associação de IES Ampla (UFC/UECE/UNIFOR). Coordenadora do Curso de Psicologia da Universidade de Fortaleza. Professora titular do curso de graduação de Psicologia da UNIFOR.

\section{Resumo}

A adolescência é considerada como uma fase de descobertas, marcada por inúmeras mudanças, e a literatura a apresenta como uma passagem da infância para a vida adulta. Os adolescentes com transtornos de aprendizagem vivenciam essa fase com medos e angústias devido aos limites que são impostos pelo transtorno. Neste estudo, objetivou-se compreender a experiência vivida de ser adolescente com diagnóstico de transtorno de aprendizagem sob a ótica da fenomenologia de Merleau-Ponty. Foi utilizado o método fenomenológico crítico para acessar a experiência vivida de adolescentes de 11 a 17 anos que participam de grupos de psicopedagogia num núcleo de atendimento integrado localizado na cidade de Fortaleza. A partir das falas dos adolescentes, foram elencadas cinco categorias: a relação do adolescente com o transtorno e suas limitações; a relação do adolescente com seu meio social; a dificuldade do adolescente em lidar com seu processo de adolescer; os sentimentos do adolescente diante de sua diferença; e a relação dos adolescentes com as exigências do cotidiano. Compreendeu-se que a experiência de ser adolescente com o transtorno é perpassada por sofrimento, uma vez que há diversos significados atribuídos como a vergonha e o sentimento de inutilidade. Considera-se que os adolescentes se encontram em um contexto no qual são destituídos e desresponsabilizados de sua própria experiência, sendo ela sempre considerada a partir de um discurso alheio por conta de uma infantilização exacerbada que, muitas vezes, é atribuída ao transtorno pelos pais e cuidadores.

Palavras-chave: adolescentes. transtorno de aprendizagem. fenomenologia. mundo vivido.

\section{Abstract}

Adolescence is considered a phase of discovery, marked by numerous changes, and literature presents it as a passage from childhood to adulthood. Adolescents with learning disorders experience this phase with fears and anxieties due to the limits imposed by the learning disorder. This study aimed to understand the experience of being an adolescent diagnosed with a learning disorder from the perspective of Merleau-Ponty's phenomenology. This study used the critical phenomenological method to access the lived experience of adolescents from 
11 to 17 years old who participate in psychopedagogy groups in an integrated care center located in Fortaleza. We listed five categories based on the adolescents'statements: the adolescent's relationship with the disorder and its limitations; the adolescent's relationship with their social environment; the adolescent's difficulty in dealing with their adolescence process; the teenager's feelings about their difference; and the relationship of adolescents with the demands of everyday life. It was understood that the experience of being an adolescent with the learning disorder is permeated by suffering since there are different meanings attributed to it, such as shame and the feeling of worthlessness. Adolescents are considered to be in a context in which they are deprived of and exempt from responsibility for their own experience, which is always considered from a foreign discourse due to an exacerbated infantilization that is often attributed to this disorder by parents and caregivers.

Keywords: adolescents; learning disorder; phenomenology; lived world.

\section{Resumen}

La adolescencia es considerada como una fase de descubiertas, marcada por muchos cambios, y la literatura la presenta como un paso de la niñez para la vida adulta. Los adolescentes con trastornos de aprendizaje viven esta fase con miedos y angustias debido a los límites que son impuestos por el trastorno. En este trabajo, se objetivó comprender la experiencia vivida de ser adolescente con diagnóstico de trastorno de aprendizaje bajo la óptica de la fenomenología de Merleau-Ponty. Se utilizó el método fenomenológico crítico para acceder a la experiencia vivida por adolescentes de 11 hasta 17 años que participan de grupos de psicopedagogía en un núcleo de atendimiento integrado ubicado en la ciudad de Fortaleza. A partir de las hablas de los adolescentes, fueron definidas cinco categorías: la relación del adolescente con el trastorno y sus limitaciones; la relación del adolescente con su medio social; la dificultad del adolescente de manejar su proceso de adolecer; los sentimientos del adolescente ante su diferencia; y la reacción de los adolescentes con las exigencias del cotidiano. Se comprendió que la experiencia de ser adolescente con el trastorno es llena de sufrimiento, una vez que hay diversos significados asignados como vergüenza y el sentimiento de inutilidad. Se considera que los adolescentes se encuentran en un contexto a lo cual son destituidos y eximidos de la responsabilidad de su propia experiencia, siendo ella siempre considerada a partir de un discurso ajeno por causa de una "infantilización" exagerada que, muchas veces, es atribuida al trastorno por los padres y cuidadores.

Palabras clave: adolescentes; trastorno de aprendizaje; fenomenología; mundo vivido.

\section{Résumé}

L'adolescence est considérée comme une phase de découverte, marquée par d'innombrables transformations. La littérature la présente comme un passage de l'enfance à l'âge adulte. Les adolescents qui présentent des troubles d'apprentissage vivent cette phase avec des peurs et des angoisses en raison des limites imposées par le trouble. Dans cette étude, nous cherchons à comprendre l'expérience d'être un adolescent diagnostiqué avec un trouble d'apprentissage du point de vue de la phénoménologie de Merleau-Ponty. La méthode phénoménologique critique a été utilisée pour accéder à l'expérience vécue par certains adolescents de 11 à 17 ans. Ils participent à des groupes de psychopédagogie dans un centre de soins intégrés situé dans la ville de Fortaleza, au Brésil. développés : la relation de l'adolescent avec le trouble et ses limites ; la relation de l'adolescent avec son environnement social ; la difficulté de l'adolescent avec son processus d'adolescence; les sentiments de l'adolescent face à sa différence et la relation des adolescents avec les exigences de la vie quotidienne. Il a été constaté que l'expérience d'être un adolescent avec ce trouble est imprégnée de souffrance, car plusieurs significations lui sont attribuées, telles que la honte et le sentiment d'inutilité. Il est possible considérer que les adolescents sont dans un contexte où ils sont privés et exonérés de la responsabilité de leur propre expérience. Cela se passe parce que leur expérience n'est considérée qu'à partir d'un discours étranger, en raison d'une infantilisation exacerbée, souvent attribuée au trouble par les parents et les soignants.

Mots-clés: adolescents ; troubles d'apprentissage ; phénoménologie ; monde vécu.

A adolescência é vista como uma fase de descobertas, marcada por mudanças no corpo, na forma de pensar e de se comportar, com presença, inclusive, de alterações biológicas desencadeadas pelo início da puberdade. Justos (2014) afirma que, nesse período, o adolescente passa a vivenciar "um aumento de exigências da sociedade, no que se refere às responsabilidades, exigência do grupo, busca de um par, definição sexual, aprendizagem de normas e conceitos sociais, escolha profissional, entre outras" (p. 236).

O referido autor afirma ainda que se trata de um momento de autoconhecimento, em que o adolescente almeja acessar tudo aquilo que lhe causa desejo, interesse e motivação, começando, dessa maneira, a confrontar pensamentos, ideias e a 
experimentar novos comportamentos, influenciando-se pelo meio no qual está inserido, e assimilando ou rejeitando, também, identificações que aconteceram no decorrer de sua vida. No entanto para alguns adolescentes essa construção de um mundo de experiências se apresenta com limitações e dificuldades que podem trazer vivências de angústia, como acontece com os que são diagnosticados com transtorno de aprendizagem (Justos, 2014; Maes et al., 2019).

Os transtornos de aprendizagem são conceituados pelo Código Internacional de Doenças (CID-11) (WHO, 2019) como transtornos específicos do desenvolvimento das habilidades escolares (6A03). Esses transtornos estão relacionados com alterações no desenvolvimento de habilidades desde estágios iniciais do desenvolvimento, decorrentes de desequilíbrios no processo cognitivo que são derivados, que podem ser desencadeados por alguma disfunção biológica (Fletcher, Lyon, Fuchs, \& Barnes, 2018).

De maneira geral, o transtorno de aprendizagem está relacionado com uma inaptidão de alguns indivíduos em atingir níveis esperados para sua idade referentes à escolarização e à capacidade intelectual. Esses transtornos não possuem uma causa específica, e podem ser irreversíveis ou reversíveis (Ohlweiler, 2016).

A fenomenologia de Merleau-Ponty foi utilizada como base para este estudo, considerando seu olhar ambíguo e mundano para o fenômeno a ser estudado: adolescência com transtorno de aprendizagem, com o intuito de problematizar a experiência com o transtorno para além da sua descrição sintomatológica.

Na filosofia de Merleau-Ponty (2006) é realizada a busca da descrição do homem no mundo e da sua experiência vivida: "O mundo é não aquilo que eu penso, mas aquilo que eu vivo; eu estou aberto ao mundo, comunico-me indubitavelmente com ele, mas não o possuo, ele é inesgotável" (p.14). Busca-se, desse modo, compreender os significados da experiência vivida em sua totalidade, em que o conceito de mundo vivido inclui o entrelaçamento da experiência objetiva com a subjetiva, sendo um importante caminho para a pesquisa fenomenológica pautada na compreensão dos significados da experiência vivida (Moreira, 2009). Por experiência entende-se um fato originário que fundamenta todo o saber e toda a ação, sendo expressão primeira do mundo vivido humano, em Merleau-Ponty:

Todo o universo da ciência é construído sobre o mundo vivido, e se queremos pesar a própria ciência com rigor, apreciar exatamente seu sentido e seu alcance, precisamos primeiramente despertar essa experiência do mundo da qual ela é expressão segunda. (p. 3)

Esta pesquisa teve, portanto, o objetivo de compreender a experiência vivida de ser adolescente com transtorno de aprendizagem sob a ótica da fenomenologia de Merleau-Ponty (2006) a partir da obra "Fenomenologia da percepção".

\section{Método}

O estudo tem como base a pesquisa fenomenológica. Esse método de pesquisa surgiu como uma proposição ao estudo dos fenômenos, sendo estes os eventos e fatos da realidade que se apresentam como fenômeno enquanto tal. Esse método propicia compreender a experiência vivida de adolescentes com diagnóstico de transtorno de aprendizagem (Creswell, 2010).

Nessa perspectiva, utilizou-se do método fenomenológico crítico que, segundo Moreira (2004, 2009), possibilita a apreensão da experiência vivida do fenômeno em seus múltiplos contornos - históricos, sociais, políticos, biológicos, culturais, entre outros. É o potencial de compreensão da experiência vivida, a partir de seus diversos significados, que transforma o método fenomenológico em ferramenta crítica.

Moreira $(2004,2009)$ afirma que um olhar crítico é fundamental para a compreensão do fenômeno psicopatológico para que não sejamos ingênuos, atentando para a sua complexidade e para as suas determinações múltiplas, constituídas, também, culturalmente e ideologicamente. O método fenomenológico crítico é inspirado na fenomenologia de Maurice MerleauPonty, cuja teoria pode ser utilizada na medida em que compreende o fenômeno da experiência vivida de forma mundana, com múltiplos contornos (Moreira, 2009).

Utilizou-se da entrevista como instrumento para apreensão da experiência de adolescentes com diagnósticos de transtornos de aprendizagem que participam de grupos de psicopedagogia ofertados semanalmente em um serviço de psicologia aplicada de uma universidade na cidade de Fortaleza, estado do Ceará. Esses grupos funcionam com a finalidade de elencar temas relevantes aos transtornos de aprendizagem, conversar sobre dificuldades enfrentadas pelos adolescentes que vivem com esses transtornos e, assim, promover a saúde desses indivíduos. Este estudo foi feito com esses indivíduos por se tratarem de um públicoalvo para intervenção psicopedagógica. Os adolescentes foram abordados diretamente pela pesquisadora, a fim de questionar sobre a participação da pesquisa. Em caso de aceite, foram contactados os responsáveis dos adolescentes para que autorizassem a participação e assinassem o Termo de Consentimento Livre e Esclarecido (TCLE).

Teve-se como pergunta disparadora: “Como é ser adolescente com o diagnóstico de transtorno de aprendizagem?" Foram entrevistados três adolescentes, pois estes foram, juntamente com seus respectivos responsáveis, os que aceitaram participar da 
pesquisa, sem a limitação de um tempo estabelecido: Bárbara, de 12 anos; Camila, de 14; e Eduardo, de 16 (nomes fictícios).

Em seguida, obedecendo às etapas do método fenomenológico crítico proposto por Moreira (2004), que possui etapas para a análise das falas obtidas nas entrevistas, a saber: transcrição literal da entrevista, que é chamada de texto nativo. O ideal é que a pessoa que transcreva seja a mesma que fez a entrevista, o que possibilita que o texto nativo contenha não apenas a fala verbal, como também as várias falas não verbais, tais como silêncios, tons de voz, choros, intervalos etc. A segunda etapa consiste na divisão do texto nativo em movimentos que seguem o tom da entrevista. Após esse passo, dá-se início à análise descritiva dos significados emergentes de cada um desses movimentos. Finalmente, a última etapa do método consiste na "saída dos parênteses", o que significa o ato de "o pesquisador volta a olhar para a sua hipótese, as suas suspeitas sobre possíveis caminhos para a compreensão de seu objeto de estudo" (Moreira, 2009, p. 126).

A partir disso, os temas foram organizados nas seguintes categorias: 1- A dificuldade do adolescente em lidar com seu processo de adolescer, que retratou como esses adolescentes vivenciam seu próprio processo de amadurecimento mediante a presença do transtorno; 2- A relação do adolescente com o mundo, em que observamos a maneira como se dá as relações entre adolescente e o mundo ao seu redor; 3- A relação do adolescente com o transtorno e suas limitações, que abarcou os sentimentos do adolescente diante de sua diferença e a relação dos adolescentes com as exigências do cotidiano.

Esta pesquisa atende à Resolução do Conselho Nacional de Saúde (CNS) n. ${ }^{\circ} 466 / 12$, cujo projeto foi aprovado pelo Comitê de Ética da Universidade de Fortaleza sob o Parecer n. ${ }^{\circ} 3.035 .871$.

\section{Resultados e Discussão}

As narrativas dos adolescentes foram organizadas em categorias e compreendidas a partir da literatura sobre o tema e sob a lente da fenomenologia de Merleau-Ponty.

\section{A Dificuldade do Adolescente em Lidar com seu Processo de Adolescer}

Os adolescentes entrevistados, em sua maioria, apresentaram-se de maneira infantilizada, percebendo-se ainda como crianças.

Aí, às vezes, eu fico brincando no meu quarto, aí eu pego e vou brincar com minhas coisas, eu sou adolescente, mas tenho mente de criança. (Bárbara)

Me sinto normal... porque o respeito é o mesmo... tudo normal... parece que pra mim eu tenho é 10 anos ainda. (Bárbara)

Porque eu fico quieta? Porque às vezes tem passeio, aí quem ficar quieta vai para o passeio. (Camila)

Tendo como base a concepção de Frota (2007), o conceito de adolescência não deve se limitar apenas à idade cronológica, às mudanças físicas e ao início da puberdade, mas deve ser pensada "como uma categoria que se constrói, se exercita e se reconstrói dentro de uma história e tempo específicos" (p. 154). Isto significa que cada adolescente possui um processo individual de construção e contato com o mundo a partir de suas experiências.

$\mathrm{O}$ adolescente, a partir de suas experiências individuais, entra em uma constante busca de conhecimento a respeito de si mesmo e do mundo, acarretando, a partir disso, sentimento de insegurança e receio em relação à identificação de suas necessidades e à realização destas no seu contato com o mundo (Melo \& Moreira, 2008).

Sendo assim, entende-se que os adolescentes em questão podem ser vistos como seres com experiências singulares e, consequentemente, com formas individuais de ver o mundo e de se mover diante do mesmo, o que é resultado de vivencias de uma realidade pessoal.

\section{Relação do Adolescente com Mundo}

Com a entrevista, foi possível perceber que os adolescentes em questão sentem-se constrangidos e acanhados diante de outras pessoas em diversas situações e, também, percebem-se bastante dependentes por estarem sempre precisando de alguém para ler e escrever para e por eles. Além disso, os adolescentes também apresentaram o sentimento de tristeza diante do olhar das pessoas para com eles diante de suas circunstâncias.

Tipo, teve a semana cultural da escola, aí teve uma sala que ela tava fazendo tipo umas tarefas, aquelas de gincanas, sabe? Aí eu fui chamado pra uma e fiquei assim... constrangido, porque eu não sabia... Fiquei com vergonha, com medo. (Eduardo) Humm... Como eu disse pra senhora, em restaurantes... Tipo assim, quando o pessoal escolhe, né, aí, tipo, eu tenho que perguntar a minha mãe o que tem pra eu escolher, porque eu não consigo ler o que tem no cardápio. (Eduardo) 
Pois é tia, á é outra dificuldade também... Porque ela (paquera/namorada) acha que você é de um jeito, mas quando ela vai ver, é outro... Tipo, quando a pessoa descobre que você não lê, ela já lhe olha com outro olhar, sabe? Não é o mesmo... (Eduardo) Eu não gosto que falem isso (A Camila não sabe ler e escrever), um dia ele não vai aprender a ler e a escrever também. (Camila) Eu sinto como se eu sempre precisasse dos outros pra me ajudar. (Bárbara)

Diante disso, Bignotto (2014) afirma que, ao longo do processo da adolescência, diversos grupos são formados, e cada um deles tem características específicas que podem estar relacionadas à maneira de se vestir e de se comportar, a aspectos físicos, aos interesses, fazendo com que exista, assim, uma homogeneidade entre os membros do grupo. Dentro desses grupos é comum a não aceitação de adolescentes que estejam fora do padrão estabelecido, o que diminui as chances de alguns adolescentes se adaptarem a contextos sociais (Maes et al., 2019). É o caso dos adolescentes entrevistados.

Estes, por terem dificuldade no processo de aprendizagem, muitas vezes acabam sendo desvalorizados pelo restante dos colegas e vistos como incapazes de fazer parte de um determinado grupo. Isto pode ser percebido por meio da fala de Eduardo, que afirma que é sempre muito difícil ter uma namorada, pois, quando ela descobre sua dificuldade, já passa a lhe olhar de outra forma e acaba o namoro, e pela fala de Camila, que afirma que tem colegas que constantemente implicam com ela pelo fato de não conseguir ler e escrever.

Merleau-Ponty (2006) aborda que o eu e o mundo estão totalmente entrelaçados, pois o "mundo já está ali, antes da reflexão, como uma presença inalienável, e cujo esforço todo consiste em reencontrar esse contato ingênuo com o mundo" (p. 1). Assim, as experiências desses adolescentes diante de seu transtorno podem ser compreendidas como entrelaçadas ao mundo que os circundam, não tendo como dizer o que é mundo, o que é adolescente e o que é sua experiência. Trata-se de uma inseparabilidade. Portanto, a maneira de ser desses adolescentes no mundo e com seus objetos está relacionada com o modo como esse mundo é percebido por eles.

Quando se pensa em transtorno, tem-se em vista seu funcionamento biológico, o que a ciência afirma e nega sobre ele, descartando, muitas vezes, a experiência de cada sujeito.

Sendo assim, "a ciência não tem e não terá jamais o mesmo sentido de ser que o mundo percebido, pela simples razão de que ela é uma determinação ou uma explicação dele" (Merleau-Ponty, 2006, p. 4), ou seja, o que é experienciado por cada adolescente vai além do que é apreendido pela ciência, uma vez que essa experiência se constitui a partir desse mundo vivido. Segundo o filósofo:

As representações científicas segundo as quais eu sou um momento do mundo são sempre ingênuas e hipócritas, porque elas subentendem, sem mencioná-la, essa outra visão, aquela da consciência, pela qual antes de tudo um mundo se dispõe em torno de mim e começa a existir para mim. (p. 4)

Nesse sentido, Merleau-Ponty (2006) traz a ideia de que:

O primeiro ato filosófico seria, então, retornar ao mundo vivido aquém do mundo objetivo, já que é nele que poderemos compreender tanto o direito como os limites do mundo objetivo, restituir à coisa sua fisionomia concreta, aos organismos sua maneira própria de tratar o mundo. (p. 89)

Diante disso, entende-se que, para entender um mundo objetivo, é necessário compreender um mundo vivido, pois é a partir do contato e da relação com este que se consegue compreender a própria relação com o resto do mundo.

\section{Relação do Adolescente com o Transtorno e suas Limitações}

Observa-se que a experiência vivida pelos adolescentes é perpassada pela vergonha de viver um transtorno de aprendizagem. Vê-se de forma clara na narrativa de Eduardo:

Quando alguém pede pra eu ler alguma coisa, sabe... Aí, eu fico assim... Envergonhado. Aí, nessas situações, eu costumo dizer que tô apressado, porque eu não consigo ler, né, aí eu invento mil e uma desculpas para não ter que passar por isso (Eduardo) Sim, sim, muitas vezes eu pego um livro e fico tentando soletrar... Mas dá um cansaço, sei lá... É, exatamente, eu fico cansado... Tipo, querer eu quero, mas, ao mesmo tempo, eu fico cansado... Aí eu fico tentando, tentando... Mas tem uma hora que não dá mais... (Eduardo)

Tia, no começo era bem difícil... Tipo, no começo eles deixavam eu lá, diziam pra eu fazer do jeito que eu sabia, e sempre eu ficava reprovado... Aí eu ficava lá... fazia, mas sabia que tava errado. (Eduardo) 


\section{Para Merleau-Ponty (2006):}

(...) minha experiência não provém de meus antecedentes, de meu ambiente físico e social, ela caminha em direção a eles e os sustenta, pois sou eu quem faz ser para mim (e, portanto ser no único sentido que a palavra possa ter para mim) essa tradição que escolho retomar, ou este horizonte cuja distância em relação a mim desmoronaria visto que não lhe pertence como uma propriedade, se eu não estivesse lá para percorrê-la com o olhar. (p.3)

Tal fala nos faz perceber um movimento em que os adolescentes são vistos quase como incapazes de dizer de sua própria experiência, sendo sempre dita sob o olhar do outro, tendo, inclusive, sua experiência pautada pelo embaraço de não conseguirem ler ou serem aprovados. Isto, por sua vez, vem de uma constante vergonha mediante o olhar do outro, o que associam ao fato de terem um transtorno, sendo imposto a eles um conjunto de significações que não são necessariamente construídas por eles, mas por outrem.

Sendo assim, entende-se que uma das maiores dificuldades do adolescente diante de seu transtorno é se ver apenas enquadrado nele, não conseguindo conceber que sua experiência e reconhecimento podem estar para além de um quadro psicopatológico, como já explicitado, sendo esse constituinte da sua forma de ser no mundo.

Nessa perspectiva, percebe-se que o sintoma ainda é reconhecido por muitos como o único caminho para se compreender quantitativamente um sujeito que está em sofrimento. Essa noção ainda é foco na psiquiatria, que, na maior parte das vezes, utiliza-se apenas do sintoma para a elaboração de um diagnóstico psiquiátrico, e acaba apreendendo nele mais do que o próprio sintoma ou do que o paciente poderia expor, apesar de este ser apenas uma pequena parcela de informações que podem ser percebidas por um médico ao entrar em contato com o paciente (Bloc \& Moreira, 2013).

Entende-se que o sofrimento dos adolescentes em questão está relacionado, também, com suas experiências com o transtorno, tendo em vista que, na maior parte das vezes, eles são enquadrados pelas pessoas ao seu redor e por eles mesmos dentro uma sintomatologia, o que acaba reduzindo o adolescente a um sintoma e perdendo de vista, assim, a compreensão global da sua forma de ser no mundo.

Merleau-Ponty (2006), acerca de uma passagem da visão ambígua, traz que:

É essa presença global da situação que dá um sentido aos estímulos parciais e que os faz contar, vale ou existir para o organismo. O reflexo não resulta de estímulos objetivos, ele se volta para eles, investe-os de sentido que eles não receberam um a um e como agentes físicos, que eles têm apenas enquanto situação. O reflexo, enquanto se abre ao sentido de uma situação, e a percepção enquanto não põe primeiramente um objeto de conhecimento e enquanto é uma intenção de nosso ser total, são modalidades de uma visão pré-objetiva, que é aquilo que chamamos de ser no mundo. (p.119)

Entende-se, portanto, que ter um transtorno toma conta da experiência global dos adolescentes em um contexto em que os sujeitos se definem por esse aspecto.

Os adolescentes mostraram sentimentos em relação as suas individualidades, como medo e receio ao que é falado e pensado a respeito deles, tais como: o sentimento de incapacidade e inutilidade, por dependerem de outras pessoas em diversas situações; a tristeza, por não terem o ritmo da maioria dos outros adolescentes; e a falta de credibilidade para com os outros e consigo mesmo. Além disso, os adolescentes também afirmaram que, às vezes, diante de todas essas circunstâncias, apresentam vontade de desistir.

Além de eu ficar com vergonha, eu fico com medo de alguém dizer assim... 'Bárbara, isso aí é tão fácil... tu não aprendeu nada?' (Bárbara)

$\mathrm{Na}$ escola é mais constrangedor ainda, porque assim, na teoria, ninguém tem esse problema. (Eduardo)

O sentimento? Sei lá, tia, acho que de amargura... que eu não sou capaz. (Eduardo)

Merleau-Ponty (2006) expõe o significado de percepção de si e do outro:

Ora, diante de mim outrem seria um em si, e, todavia ele existiria para si, para ser percebido ele exigiria de mim uma operação contraditória, já que ao mesmo tempo eu deveria distingui-lo de mim, portanto situá-lo mundo dos objetos, e pensá-lo como consciência, quer dizer, como essa espécie de ser sem exterior e sem partes ao qual só tenho acesso porque ele sou eu, e porque nele se confundem aquele que pensa e aquele que é pensado. (p. 468)

E continua: 
Portanto, no pensamento objetivo não há lugar para outrem e para uma pluralidade de consciências. Se eu constituo o mundo, não posso pensar outra consciência, pois seria preciso que ela também o constituísse e, pelo menos em relação a esta outra visão sobre o mundo, eu não seria constituinte. Mesmo se eu conseguisse pensá-la como constituindo o mundo, seria eu ainda que a constituiria como tal, e novamente eu seria o único constituinte. (p. 468)

Nessa passagem, o autor traz a ideia de que o eu, o outro e o mundo estão entrelaçados, já que, a partir do momento que eu penso na possibilidade de outra existência, ainda sou eu que estou constituindo-a. Portanto, pode-se perceber por meio do relato dos adolescentes entrevistados, que o sofrimento e a forma como estes se percebem, como se veem no mundo, tem a ver a forma como eles compreendem o próprio mundo.

Uma vez compreendido com Merleau-Ponty (2006) que o mundo vivido já está posto (“O mundo já está sempre "ali", antes da reflexão" (p.1)), a descrição é a poderosa ferramenta para se acessar a experiência direta dos indivíduos. Assim, no ato descrição, os adolescentes podem acessar sua própria experiência de estar no mundo, construindo sentidos e os compreendendo, uma vez que:

É a tentativa de uma descrição direta de nossa experiência tal como ela é, e sem nenhuma deferência a sua gênese psicológica, e às explicações causais que o cientista, o historiador ou o sociólogo dela possam fornecer. (p.1)

Nesse sentido, compreende-se que o transtorno de aprendizagem é constituinte do mundo vivido dos adolescentes em questão, já que, segundo Ohlweiler (2016), "os padrões normais de aquisição de habilidades estão perturbados desde os estágios iniciais do desenvolvimento, ou seja, não são adquiridos em decorrência de falta de estimulação adequada ou de qualquer forma de traumatismo ou doença cerebral" (p. 108). A aquisição do aprendizado, nesse caso, está atrelada a questões multifatoriais, desde socioculturais, econômicas, familiares, emocionais e pedagógicas (Peixoto, Tinoco, Erthal, \& Luquetti, (2019).

Pode-se pensar que essas questões se tornam ainda mais complexas quando se discute o que é normal e patológico. Para Bloc e Moreira (2016), tais conceitos não devem ser compreendidos como algo da ordem do ideal, do coletivo, ou daquilo que pode ser comum a todas as pessoas, estando relacionadas à cultura em que os sujeitos estão inseridos. Para os autores, o patológico e normal está relacionado com a maneira como o sujeito lida com seus conflitos, relacionando ao conceito de liberdade e autonomia em que o indivíduo acometido por uma patologia "perde sua potencialidade, ficando estagnado e sem um equilíbrio entre autonomia e heteronomia" (p.166).

A questão do enquadre no que se consideraria "anormal" pode ainda ser notado, sobretudo no contexto em que muitos adolescentes podem se considerar como anormais. No entanto sabe-se que esse enquadre acaba dificultando ainda mais seu processo, e que, muitas vezes, o que deveria ser visto como uma dificuldade inerente ao adolescente e passível de crescimento acaba sendo aumentada e supervalorizada.

Os adolescentes apresentaram grande dificuldade em lidar com as exigências do cotidiano, principalmente ao se tratar de atividades e provas escolares, pois se sentem, muitas vezes, inferiores aos outros por precisarem de ajuda constantemente e por estudarem e, na maioria das vezes, não alcançarem o resultado que gostariam (Fletcher et al., 2018). Além disso, os adolescentes acreditam que o que aprendem não é suficiente para atender às suas expectativas e às dos outros.

Fazem a tarefa só, não precisam de ninguém... Entendeu? Eu não, eu sempre vou precisar de alguém ou então eu vou saber que tá errado. (Eduardo)

Tia, tipo, eu não gosto muito de conversar sobre essas coisas, sabe? Eu me sinto, tipo, sei lá, me sinto como se eu fosse menos que os outros, como se eu não tivesse a mesma capacidade dos outros... Eu acho que eu fico mais rebaixado. (Eduardo)

Não... É porque todo mundo fazendo tudo só e eu pedindo ajuda!?” (Bárbara)

-Porque, às vezes, eu queria tanto tirar nota alta, aí, do nada, quando eu dou fé, eu tiro nota baixa (Bárbara)

Nesse sentido, Tricoli (2014) afirma que as mudanças que acontecem na vida dos adolescentes contribuem bastante para seu desgaste excessivo para tentar atender às exigências adaptativas do cotidiano, o que os leva, muitas vezes, ao estresse, à ansiedade, à insegurança. Diante disso, Crestani (2016) alega que, nessa fase, é fundamental que pais e educadores ajudem os adolescentes a reconhecerem suas potencialidades, fazendoos aprender a caminhar e a se mover diante de um conflito ou de um ambiente hostil.

Pode-se, portanto, dizer que os diferentes contextos que circundam os adolescentes podem dificultar ou ajudar significativamente o processo de aprendizagem deles, de tal forma que uma pequena dificuldade pode virar uma grande dificuldade quando não se tem auxílio e compreensão, assim como uma grande dificuldade pode ser minimizada quando acompanhada e compreendida de forma efetiva (Diniz, 2013). 
Diante disso, segundo Diniz (2013), é possível perceber que os adolescentes estão cada vez menos disponíveis para aprender, visto que vivem diante de medos, precisando dispor da maior parte da sua energia mental para se proteger. Dessa maneira, eles acabam não sabendo utilizar sua capacidade intelectual a seu favor, mostrando pouco interesse e curiosidade em aprender, devido, muitas vezes, à falta de autoconfiança.

\section{Considerações Finais}

Ante o exposto, foi possível compreender que os adolescentes com o diagnóstico de transtorno de aprendizagem experienciam um grande sofrimento por consequência das suas singularidades. Por apresentarem algumas limitações, percebem-se, muitas vezes, como sujeitos incapazes, já que não conseguem acompanhar o ritmo que a sociedade espera e, também, que eles mesmos almejam. Com isso, esses adolescentes acabam enfrentando desafios ainda maiores no que diz respeito ao desenvolvimento da aprendizagem, pois, ao acreditarem que não conseguem aprender, acabam desmotivados para lidar com suas questões.

Além disso, entende-se que ainda existe muito preconceito no que diz respeito à visão da sociedade para com esses adolescentes. Esta ainda costuma enquadrá-los dentro de uma sintomatologia, tornando-se, assim, incapaz de conseguir enxergar esses adolescentes para além de seus sintomas. Essa visão acaba influenciando diretamente na percepção dos adolescentes para com eles mesmos, já que, ao serem reconhecidos como sujeitos "anormais" e insuficientes, também acabam se percebendo dessa maneira. Afinal, para os adolescentes em questão, lidar com o transtorno é lidar com o diferente, e lidar com o diferente é lidar com o sofrimento.

Nessa perspectiva, os adolescentes com o diagnóstico de transtorno de aprendizagem apresentam uma grande resistência frente ao seu processo de adolescer como resultado de suas experiências, muitas vezes, frustrantes com o mundo. Faz parte dessa experiência também o despreparo das escolas para lidar com esse tipo de dificuldade.

Desse modo, é possível considerar que os adolescentes em questão, por todas as dificuldades enfrentadas na sua relação com o mundo e consigo mesmo, parecem estar cada vez menos disponíveis para aprender, já que, ao precisarem lidar constantemente com seus medos e inseguranças, acabam por precisar dispor de grande parte da sua disponibilidade para viver. Esses adolescentes apresentam, assim, grande sofrimento perante suas limitações e, também, grande dificuldade para perceberem suas potencialidades e seus valores.

\section{Referências}

Bignotto, M. M. (2014). O bullying. In M. Lipp (Org.), O adolescente e seus dilemas: Orientação para pais e educadores (pp. 109-124). Campinas, SP: Papirus.

Bloc, L., \& Moreira, V. (2013). Condições para a mudança psicoterapêutica e intervenções fenomenológicas: Reflexões a partir do caso Fátima. In V. Moreira (Org.), Revisitando as psicoterapias humanistas (pp. 49-60). São Paulo, SP: Intermeios.

Bloc, L., \& Moreira, V. (2016). O normal, o patológico e a cultura. In A. Tatossian, L. Bloc, \& V. Moreira, Psicopatologia fenomenológica revisitada (pp. 161-174). São Paulo: Escuta.

Crestani, I. A. (2016). Adolescência: Tentando compreender o que é dificil entender. Porto Alegre, RS: EDIPUCRS.

Creswell, J. W. (2010). Projeto de pesquisa: Métodos qualitativo, quantitativo e mistos. Porto Alegre: Artmed.

Diniz, M. M. F. (2013). Dificuldades de aprendizagem: análise conceitual. In C. A. S. M. Minervino, \& J. N. Nóbrega (Orgs.), Aprendizagem e emoção: Estudos na infância e da adolescência (pp. 93-114). São Paulo, SP: Casa do Psicólogo.

Fletcher, J. M., Lyon, G. R., Fuchs, L. S., \& Barnes, M. A. (2018). Learning disabilities: From identification to intervention. Nova Iorque: Guilford Publications.

Frota, A. M. M. C. (2007). Diferentes concepções da infância e adolescência: A sua importância da historicidade para sua construção. Estudos e Pesquisas em Psicologia, 7(1), 144-157.

Justos, A. P. (2014). O desafio da escolha profissional. In M. Lipp (Org.), O adolescente e seus dilemas: Orientação para pais e educadores (pp. 235-252). Campinas, SP: Papirus. 
Maes, M., Nelemans, S. A., Danneel, S., Fernández-Castilla, B., Van den Noortgate, W., Goossens, L., \& Vanhalst, J. (2019). Loneliness and social anxiety across childhood and adolescence: Multilevel meta-analyses of cross-sectional and longitudinal associations. Developmental psychology, 55(7), 1548-1565.

Melo, A. K. S., \& Moreira, V. (2008). Fenomenologia da queixa depressiva em adolescentes: Um estudo crítico-cultural. Aletheia, 27(1), 51-64.

Merleau-Ponty, M. (2006). Fenomenologia da percepção ( $3^{\mathrm{a}}$ ed.). São Paulo: Martins Fontes. (Originalmente publicado em 1945)

Moreira, V. (2004). O método fenomenológico de Merleau-Ponty como ferramenta crítica na pesquisa em psicopatologia. Psicologia: Reflexão e Crítica, 17(3), 447-456.

Moreira, V. (2009). Clínica humanista-fenomenológica: estudos em psicoterapia e psicopatologia crítica. Annablume.

Ohlweiler, L. (2016). Introdução aos transtornos da aprendizagem. In N. T. Rotta, L. Ohlweiler, \& R. S. Risgo (Orgs.), Transtornos de aprendizagem: Abordagem neurobiológica e multidisciplinar ( $\left.2^{\mathrm{a}} \mathrm{ed} ., \mathrm{pp} .107-111\right)$. Porto Alegre, RS: Artmed.

Peixoto, P., Tinoco, D., Erthal, A. \& Luquetti, E. (2019). A dislexia no processo de ensino e aprendizagem da leitura e escrita: Considerações sobre a prática educacional. Revista Philologus, 25(73), 44-62.

Tricoli, V. A. C. (2014). O stress emocional e seus efeitos. In M. Lipp (Org.), O adolescente e seus dilemas: Orientação para pais e educadores (pp. 157-177). Campinas, SP: Papirus.

World Health Organization [WHO]. (2019). ICD-11 - Mortality and Morbidity Statistics. Genebra: WHO. Link

\section{Como citar:}

Ibiapina, R. P. M., Leite, J. M. A., \& Melo, A. K. (2021). Ser Adolescente com Transtorno de Aprendizagem: Um Olhar da Fenomenologia de Merleau-Ponty. Revista Subjetividades, 21(Esp 1. Psicologia \& Fenomenologia), e9376. http://doi. org/10.5020/23590777.rs.v21iEsp1.e9376

\section{Endereço para correspondência}

Roxanne Pucci de Mesquita Ibiapina

E-mail: roxannepucci@hotmail.com

João Marcos de Araújo Leite

E-mail: joaomarcosleite09@gmail.com

Anna Karynne Melo

E-mail: karynnemelo@unifor.br

Recebido em: 03/05/2029

Revisado em: $28 / 09 / 2020$

Aceito em: 28/01/2021

Publicado online: 19/06/2021 